OnLine Journal of Biological Sciences 10 (1): 17-35, 2010

ISSN 1608-4217

(C) 2010 Science Publications

\title{
Complexity in Human Perception of Brightness: A Historical Review on the Evolution of the Philosophy of Visual Perception
}

\author{
${ }^{1,2}$ Kuntal Ghosh and ${ }^{3}$ Kamales Bhaumik \\ ${ }^{1}$ Machine Intelligence Unit, Indian Statistical Institute, Kolkata, West Bengal, India \\ ${ }^{2}$ Center for Soft Computing Research, Indian Statistical Institute, Kolkata, West Bengal, India \\ ${ }^{3}$ Faculty of Science, West Bengal State University, North 24-Parganas, West Bengal, India
}

\begin{abstract}
Problem statement: The "eye-brain" complex, which contributes maximally to visual perception, is no doubt a very interesting object for complexity study. In this review we shall try to present some of its aspects in perceiving brightness. It is a well-known fact that the perceived brightness of any surface depends on the brightness of the surfaces that surround it, a phenomenon termed as brightness induction. Several studies reveal that brightness contrast and brightness assimilation are two opposite phenomena in brightness induction. The former can be explained through the microscopic neural circuits that emanate from the retinal ganglion cells and converge on to primary visual cortex i.e. through a bottom-up approach, something which however fails till date to account for the later. In search of a unified theory of brightness induction, a top-down approach has often been suggested. However, the mechanism of brightness induction evident in several optical illusions, is not yet understood even after 200 years of intense research that saw George Berkeley, Maxwell, Helmholtz and the modern Gestalt school, that include both the intrinsic image theorists as well as the anchoring model theorists, following the "top-down" approach on one hand and Weber, Fechner, Mach, succeeded by the modern contrast theorists following the "bottom-up" approach on the other. Approach: In this review, we presented a historical perspective of the evolution of human concepts about the perception of brightness. We tried to capture the two essential philosophical trends among the scientists in understanding the phenomenon of brightness induction. The problems with idealist approach as well as the limitations of the mechanical materialist approach, have been pointed out in the light of the facts that, nature in general and complex systems in particular, are intrinsically dialectic in nature. Results: A proposal had been put forward that the path of dialectical materialism is the possible way out for the present philosophical crisis. Conclusion: Lateral inhibition based contrast theories need to be substantiated not only by the basic law of dialectics on which it rests upon viz., the unity of opposites, but also through the incorporation of the other dialectical laws like connectivity, quantity-quality transition and negation of the negation, so as to challenge all sorts of mysticisms in vision science and in brightness perception domain. Some recent researches both in experimental psychophysics as well as in mathematical modeling, that have been discussed or referred to in this review, are showing signs of such a development. In order to ensure that such synthesis should be dialectic and not eclectic, it would require identifying the proper mathematics towards quantitatively representing complex phenomena, a mathematics that can quantify the interaction between the part and the whole, through dialectical rules.
\end{abstract}

Key words: Visual perception, brightness contrast, brightness assimilation, low-level models, highlevel models, dialectical materialism

\section{INTRODUCTION}

Complex systems are intrinsically dialectic in nature. The word complex stems from the Latin word complexus, meaning "twisted together", which emphasizes presence of more than one component that interact with one another to generate an emerging property. Even in English the word 'complex' means a system made of closely connected components. In such systems the individualities of the components are preserved. However interactions between the components generate novel behavior of the system, which can never be predicted by summing up the properties of the individual components. The inherent

Corresponding Author: Kuntal Ghosh, Machine Intelligence Unit, Indian Statistical Institute, Kolkata, West Bengal, India 
contradiction between the independent behavior of the parts and the mutual control of one part on the other through network connectivity, gives rise to the emerging properties of the complex systems. There is probably little debate on the above description in assigning the qualities of a complex system. The debate lies in arriving at a quantitative measure of complexity. No doubt a system will become more complex either by increasing the number of its components or by increasing the connectivity between the components. Disagreement lies in fitting these two factors in an appropriate formula to arrive at a quantitative number. Without entering into such controversies, one may accept that even from a common sense view, one system may be termed as more complex than another system. If such an ordering is permitted, then one can safely make a statement that biological systems, from some particular perspectives, are more complex than most of the non-biological systems. Among the biological systems, the human body and its functions are extremely complex. Brain, consisting of millions of interconnected neurons, is perhaps the most complex organ among the human body. Hence the "eye-brain" complex, which contributes maximally to the visual perception, is no doubt a very interesting object for complexity study. In this review we shall try to present some aspects of this eye-brain complex in perceiving brightness. We shall present here a historical perspective of the evolution of human concepts about the human perception of brightness.

Most of the vision scientists, who in the nineteenth century attempted to propose mathematical models for the process of visual perception, ended up (consciously or unconsciously) as staunch opponents to the materialist school. It is surprising, because these scientists were sincerely engaged in trying to understand and model the processing of information in the eye-brain system in contradiction to the other philosophers who wanted to mystify the objective phenomenon of the complexity of the brain by portraying a picture based on crude subjectivism. Such philosophers may bluntly or subtly put the mind before the matter like putting cart before the horse, but for vision scientists the basic premise would have been to consider matter as primary and mind (or concept of it) as secondary (Tse Tung, 1937).

Let us start our journey from the earlier research on human understanding about the mechanism of human perception of brightness. We begin with the seminal study of Gustav Theodor Fechner (1801-1887), the founder of the discipline of psychophysics (Dember, 1964). The philosophical background of Fechner was imprinted with the controversies between rationalist
Descartes (1596-1650) and empiricist Francis Bacon (1561-1626) and also the research of Immanuel Kant (1724-1804) who wanted to create a compromise between the rationalists and empiricists. Descartes based his entire approach only on the purity of mathematical equations (Anderson, 2005). Algebra and geometry, he claimed, were all that he required in arriving at truth. This view was in complete contradiction to the empiricist viewpoint, wherein only experimentally verified facts were used to arrive at objective truth. Descartes posed the supreme role of theory (mathematics) antagonistically to that of experiments and thus ended up in the idealist camp (for whom mind is foremost and matter secondary).

The most significant contribution of Fechner is the demonstration that mind or perception is susceptible to measurement and mathematical treatment and hence psychology has the potential to become a quantifiable science in contrast to the doctrine of idealist theorists such as Immanuel Kant (Mandler and Mandler, 1964), who believed in the impossibility of existence of anything called as science of psychology. Not only did Fechner investigate the mind-body problem, he even went on to propose an exact mathematical relation between them. The most famous outcome of his inquiries is the law known as the Weber-Fechner law which may be expressed as follows:

\section{"In order that the intensity of a sensation may increase in arithmetical progression, the stimulus must increase in geometrical progression"}

Fechner's law implies that sensation is a logarithmic function of physical intensity, i.e., mathematically:

$\mathrm{S}=\mathrm{k} \log \mathrm{R}$

Here:

$\mathrm{S}=$ Sensation

$\mathrm{R}=$ The stimulus numerically estimated and

$\mathrm{k}=\mathrm{A}$ constant that must be separately determined by experiment in each particular order of sensibility.

Unlike Descartes therefore, Fechner, despite his love for mathematical abstractions, remained a devoted experimental psychologist and yet, curiously enough, somehow managed to end up in the same idealist camp. This actually resulted from his vacillation in concluding that $\mathrm{R}$ is primary and hence is body in the mind-body problem, thus surrendering to the more veiled brand of idealism viz., dualism of mind and matter. This vacillation of Fechner existed in spite of the fact that 
the Weber-Fechner law had been found to be immensely useful within significant limits, like for example the logarithmic compression of intensity levels in the photoreceptor layers of our visual system. In fact Fechner actually continued the good research of E.H. Weber (1795-1878) who stated:

"The ratio of the increment threshold to the background intensity is a constant"

So mathematically:

$$
\frac{\Delta \mathrm{I}}{\mathrm{I}}=\mathrm{c}
$$

This ratio is often termed as the Weber fraction. Weber and Fechner were both highly accomplished experimental psychologists and should have been strong opponents of Descartes' views on the supposed supremacy of purity of thought. They actually belonged to the data-driven information processing approach of the structuralist school where experiments and data were used as the primary sources in arriving at truth. Moreover, it was their ability to abstract out mathematical laws from such experiments that enabled them to dissociate themselves from the absolutism of reductionist approach, i.e., mechanical materialism (what Fechner called 'the night view'). However, at the same time, their aptitude in performing mathematical abstraction trapped them within the absolutism of Descartian thought process where equation (macro) was considered as almighty and physical reality (micro) as its mere follower.

Fechner was indeed the forerunner of Ernst Mach (1838-1916), another brilliant experimental physicist, in the domain of vision and perception. Mach, who is very relevant to our present discussion, proposed a mathematical model of visual perception from retinal images (Ratliff, 1965). He stated:

"Let us call the intensity of illumination $u$ on a uniform mat plane where $\mathrm{u}=\mathrm{f}(\mathrm{x}, \mathrm{y})$. Thus, the brightness sensation $v$ of the corresponding retinal point is given by:

$$
v=u-m\left(d^{2} u / d x^{2}+d^{2} u / d y^{2}\right)
$$

where, $\mathrm{m}$ is a constant. If the expression in brackets is positive, then the sensation of brightness is reduced; in the opposite case, it is increased. Thus, $v$ is not only influenced by $\mathrm{u}$, but also by its second differential quotients".
Mach's model is a brilliant example of generating a successful mathematical model on the basis of empirical data. His experimental observations like Mach Band could also be explained with this model. However, Mach too gradually got drifted from the path of scientific materialism to a pseudo-scientific idealist philosophy like empirio-criticism. The schools of Weber, Fechner and Mach were pioneer in proposing new mathematical model of visual perception based upon psychophysical and neurophysiological experimental observations. They believed in structuralism, based their model on experimental observations but curiously deviated towards the trap of idealism.

All this while, alongside the presence of structuralism in visual perception and its deviation into the realms of idealism, there had long been an information-or knowledge-driven constructivist thought process propagated by the likes of James Clerk Maxwell (1831-1879) and Herman von Helmholtz (1821-1894) (Dember, 1964). Helmholtz argues that the data provided by our senses are inadequate and are augmented by unconscious inferences, which add meaning to sensory data. He assumes these inferences to be unconscious because we typically have no awareness that we are making such inferences while perceiving. According to this constructivist approach, perception is not directly given by stimulus input, but occurs as the end-product of the interactive influences of the presented stimulus and certain internal hypothesis, expectation and knowledge, as well as motivational and emotional factors. It is obvious that such incorporation of mind and emotion in analyzing the empirical observations clearly dilutes the very basis of science, namely the objectivity of experiments. In spite of that the constructivist approach was very popular and its flavor has not yet died down. Even in recent times it is echoed by Gregory (1972), who claims that perceptions are constructions:

"From floating, fragmentary scraps of data signaled by senses and drawn from the memory banks, themselves constructions from the snippets of the past"

or in more recent times by Chalmers (1996), who introduces the concept of snippets of consciousness or qualia. In spite of some definite positive aspects associated with the idea of perception as an act of unconscious inference and likelihood principle as envisaged by Helmholtz, this approach dissociates itself from low level data-driven neurophysiological or 
computational approaches initiated by the proponents of structuralism and thus fell prey to solipsism.

In between these two opposing approaches, emerged the Gestalt school of thought for whom perception follows a minimum principle and is at the same time holistic. According to the Gestalt psychologists like Koffka (2004), the elementary features in a visual scene are locally bound together into coherent groups on the basis of such coherence criteria as Proximity, Similarity, Continuity, Common fate and Closure. By Proximity is meant that an object is not scattered all over, rather all its parts are near each other. Collections of objects are not considered together unless they are near each other, either spatially or temporally. By Similarity is meant, the elements are grouped together with elements that have the same or similar features, i.e., any two parts of the same simple object probably look alike. Continuity means an element is a part of that object which gives the most continuous border. Consequently, the next element of a set can be determined from the preceding elements.

In visual perception, one may identify two distinct groups of workers following two quite distinct philosophical approaches. One is the school of Maxwell, Helmholtz or Gestalt philosophers, who follow a "top-down" approach that explains the observations in the light of high-level perceptual groupings. The other one is the school of Weber, Fechner or Mach, who follow a "bottom-up" approach that explains the observations in the light of low-level perceptual groupings like neurophysiological microscopic connectivity. As a small digression, it may be noted that both of these opposing schools were able to grasp the essence of complex system. Gestalt theories always believed that "whole is not mere sum of its parts", whereas Fechner proposed the theory of selforganization, leading to the principle of emergent behavior (Heidelberger, 2004). We shall in this study restrict ourselves to the locus standee of these two schools with respect to various psychophysical experiments concerning the phenomenon of brightness perception only.

Brightness induction is directional: It is a well-known fact that the perceived brightness of any surface depends on the brightness of the surfaces that surround it, a phenomenon termed as brightness induction. Several studies by Helson (1963); Hong and Shevell (2004); Jameson (1985); Jameson and Hurvich (1989) reveal that brightness contrast (Fig. 1) and brightness assimilation (Fig. 2) are two opposite phenomena of spatial frequency dependent brightness induction. When the stimulus mainly loses its low frequency content due to spatial filtering by high spatial frequency tuned channels, brightness contrast appears. On the other hand if the low spatial frequency tuned channels mainly filter out the high frequency content of the stimulus, it results in brightness assimilation. It will be worthwhile, at this point of time, to recall once again from Mach (Ratliff, 1965):

"The illumination of a retinal point will, in proportion to the difference between this illumination and the average of the illumination on neighboring points, appear brighter or darker, respectively depending on whether the illumination of it is above or below that average. The weight of the retinal points in this average is to be thought of as rapidly decreasing with distance from the particular point considered"

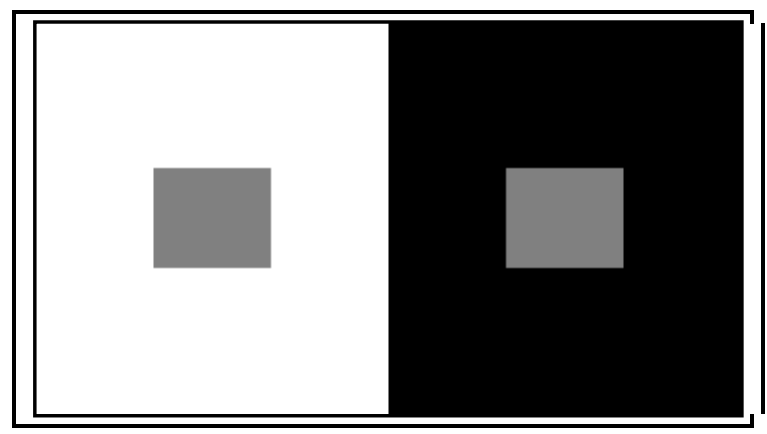

Fig. 1: Demonstration of simultaneous brightness contrast in the two test patches, so that test patches of the same gray scale values are perceived brighter or darker i.e., in opposite direction of their background brightness

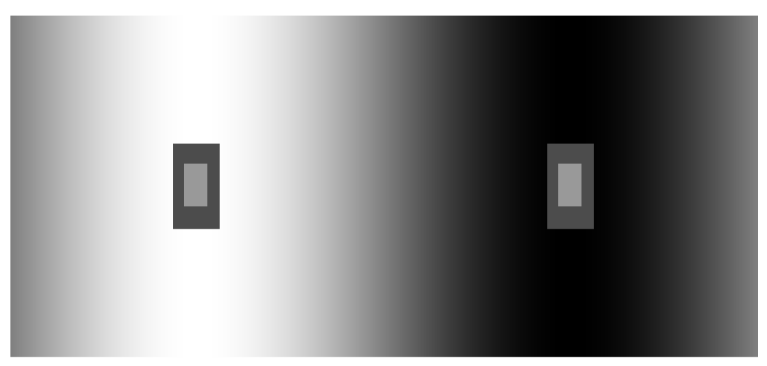

Fig. 2: Demonstration of brightness assimilation: The innermost test patches are perceived in the same brightness direction as their immediate backgrounds, i.e., the outer test patches, which themselves however exhibit brightness contrast 


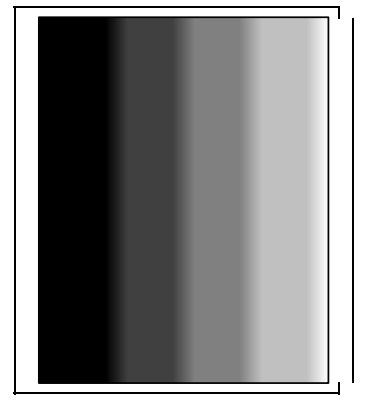

Fig. 3: Demonstration of Mach bands in a horizontally trapezoidal stimulus: The illusory bright and dark bands are clearly visible

Almost a complete century passed after these words were uttered, when the probing microelectrodes of two groups of physiologists, Rodieck and Stone (1965); Enroth and Robson (1966) discovered the truth of this scientific prophecy. In the first half of the twentieth century Hartline (1940) had pioneered the concept of visual receptive field that was increasingly proving out to be quite successful in understanding the system at early levels up through the simple striate cortex neurons. Its usefulness depended upon the system being considered as a linear and basically feedforward one. Such a feed-forward neural model in which the selectivity of a neuron in a higher order area, is supposed to be constructed by the ordered arrangement of feed-forward inputs from lower order areas inspired Hubel and Wiesel (1962) to provide explanation to the orientation selectivity of cortical cells in layer V1 as due to the ordered arrangement of the inputs from the retinal ganglion and the Lateral Geniculate Nucleus (LGN) relay cells. Hubel and Wiesel (1962) systematically established the excitatoryinhibitory structure of the ganglion or LGN receptive field. However, it is clear from the above quotation of Mach that this structure was long foreseen by him. Thus he was aware of this striking example of dialectics in nature (Engels, 1883), though in the later years he opposed the school of dialectical materialism (Lenin, 1908). On the basis of this concept, Mach created 'Mach Bands', which generally comprised of appearance of pseudo dark and light bands on rotating discs. Ratliff later demonstrated the same in static images also, which comprised of horizontally trapezoidal stimuli (Ratliff, 1965; Ratliff and Hartline, 1959) (Fig. 3).

Let us now come back to the discussion on the works of Rodieck and Stone (1965); Enroth and Robson (1966). After extensive experimental research on center-surround receptive fields, they put forward a mathematical model different from the one as given by Eq. 3. They proposed a Difference Of Gaussian (DOG) model comprising of two Gaussian functions of varying variances, the smaller of which represented the centre and the larger, the surround. The model was almost similar to the one based on second order differential, as proposed by Mach, but included a smoothing function. Necessity of having a smoothing function was stated by Mach, but he never explicitly used such function in his model. About fifteen years later, Marr (1982) proved the identity between the two models. Marr demonstrated that under certain approximations, the Laplacian operator used by Mach, when applied on a Gaussian function, yielded a function that almost coincided with the DOG. Marr thus completed Mach's own proposal by combining Mach's Laplacian operator with a Gaussian smoothing function. However, this DOG or LOG (Laplacian of Gaussian) operator could explain only one of the directions of brightness induction, viz., brightness contrast and not brightness assimilation (Palmer, 1999; Ratliff, 1965). Marr and Hildreth (1980) applied the LOG operator in zero-crossing i.e., edge extraction and since visually edges exist in various scales, coarse or fine, depending upon in which part of the visual field attention is focused, he suggested:

"If a zero-crossing segment is present in a set
of independent LOG channels over a
contiguous range of sizes and the segment has
the same position and orientation in each
channel, then the set of such zero-crossing
segments indicates the presence of an intensity
change in the image that is due to a single
physical phenomenon (a change in reflectance,
illumination, depth, or surface orientation)"

We thus see that David Marr was probably the first vision scientist who tried to relate the differential approach (breaking into edges) in vision with the integrative approach of connecting the part with the whole or the individual with the system, in a quantified manner. $\mathrm{He}$ is indeed the modern father figure in understanding visual complexity. From here also emerged the concept of multi-scale LOG or DOG filters and the possible existence of an array of such filters in the simple cells of primary visual cortex. Probably spurred on by these developments, Jameson (1985); Jameson and Hurvich (1989) and later Kingdom and Moulden (1992) proposed a multi-scale spatial filter model of primary visual cortex in a bid to account for the opposite nature of brightness induction. Kingdom and Moulden proposed that V1 cortical output is a resultant of spatial filtering through four multiscale DOGs. 


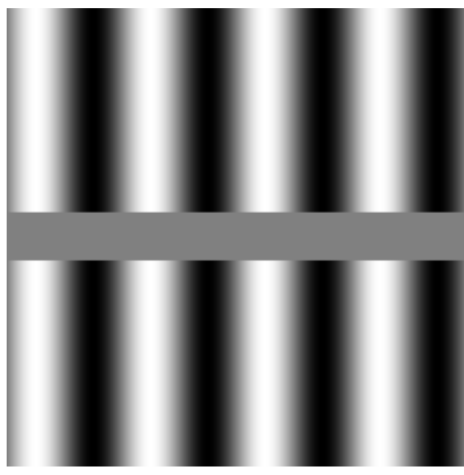

Fig. 4: Demonstration of Grating induction illusion: brightness profile of the horizontally sinusoidal background has been induced in opposite phase into a uniform test patch in the foreground

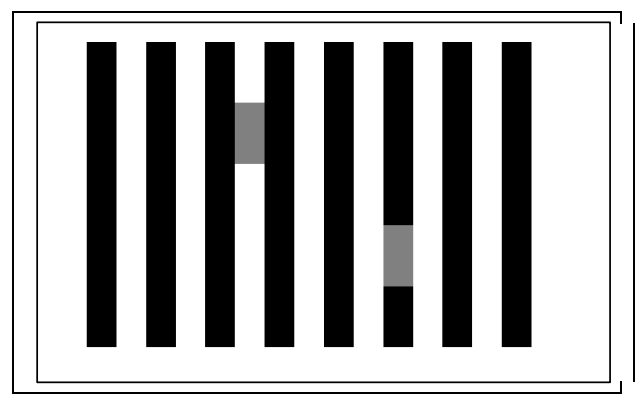

Fig. 5: The White effect stimulus that completely defies the theory of lateral inhibition

This approach was further carried forward by Blakeslee and McCourt (1997) who proposed to compute the V1 cortical output through a linear combination of seven octave-interval DOG filters, including more low frequency tuned DOG functions to the multi-scale spatial filters of Kingdom and Moulden (1992). With this modified model, they provided an explanation to both brightness contrast and assimilation effects along with the low spatial frequency response of Grating Induction (GI) (McCourt, 1982) (Fig. 4) and the invariance of induction magnitude with viewing distance.

Meanwhile another interesting case on brightness induction came up, known as White's stimulus (White, 1979; 1981), which is a square wave grating, consisting of black and white bars. Parts of a white and a black bar are replaced by identical gray patches. The gray segment on the white bar looks darker than that on the black bar (Fig. 5). White unfurled that for this stimulus, the direction of brightness change does not depend on the amount of black or white border in immediate contact with the gray test patch, or in its general vicinity.

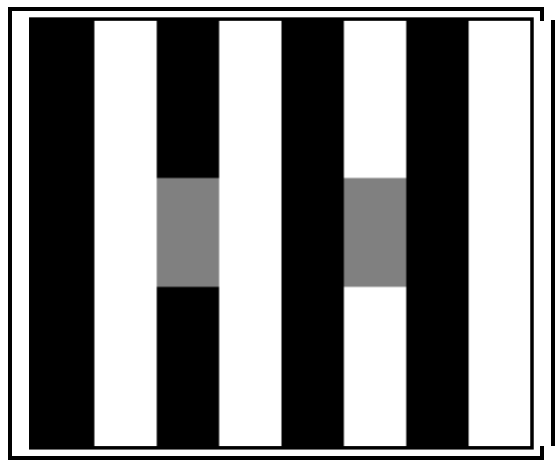

Fig. 6: The White effect remains evident even at a lower spatial frequency

Though the test patch on the white bar has more border contact with the black flanking bars, it appears darker than the one on a black bar, thus ruling out an explanation based on lateral contrast with the black flanking bars. The direction of induced brightness change also remains unaltered even if the height of the test patch gets reduced to enable it to have more amount of border contact with the coaxial bar on which it is situated. It appears that brightness induction follows the direction of brightness contrast along the coaxial bar on which it is situated. The observation of White effect is therefore suggestive of the fact that brightness of the gray test patches shifts towards the brightness of the flanking bars rather than the coaxial bars on which they are situated. White and White (1985), while experimenting with the phase shift of the gray test patches relative to the flanking bars, came up with a notion that at higher spatial frequency of the grating, White effect might result from brightness assimilation. But what is queer is that the White effect remains evident even at lower spatial frequency (Fig. 6), although some experimentalists demonstrated that for shifted White effect which is sometimes called the checkerboard stimulus, brightness induction indeed changes direction with frequency. Thus probably, 'there are more things in' understanding brightness perception than the suggestion put forth by Blakeslee and McCourt (2004). The suggestion states that patterns whose scales are larger (i.e., of low spatial frequency) relative to the scale of the encoding filters, are represented with a loss of low frequency information and as such exhibit brightness contrast; while patterns whose scales are smaller (i.e., of high spatial frequency) relative to the scale of the encoding filters, are represented with a loss of high frequency information and as such exhibit brightness assimilation. The contradictions posed by the White effect in understanding brightness perception initially led Blakeslee and McCourt (1999) to 
incorporate the aspect of orientation in their multi-scale model (ODOG). Later they included global contrast normalization into their model (Blakeslee and McCourt, 2004), leading subsequently first to the Locally Normalized ODOG model (LODOG) and finally to the Frequency-specific LODOG model (FLODOG) by Robinson et al. (2007). It is very disturbing to note from the history of these models that in order to explain new observations, the tendency was to increase the number of parameters instead of finding out any qualitative change in the modeling. It is clear, therefore, that either the "bottom-up" approach of the neurophysiologists or the "top-down" approach of the psychologists failed to find out any other key feature in visual perception beyond contrast sensitivity. Possibly, the same 'specter is haunting' vision science once again. The specter of mechanical materialism or reductionism is not yet dead. It would also be interesting to study how the increasing reductionism has in turn spurred the Gestalt psychologists in rejecting low-level spatial filtering altogether and resort to 'higher level perceptual groupings'.

High level models of brightness induction: The high level models in vision originated even prior to Helmholtz. This was the advancement of the theory of immaterialism by George Bishop Barkeley. He wrote a book An Essay towards a New Theory of Vision, (Barkeley, 1709) followed by another book A Treatise Concerning the Principles of Human Knowledge, (Barkeley, 1760), where he promulgates his views against materialism:

"It is indeed an opinion strangely prevailing amongst men, that houses, mountains, rivers and in a word all sensible objects have an existence, natural or real, distinct from their being perceived by the understanding"

He goes on to say:

"For, what are the afore-mentioned objects but the things we perceive by sense? And what do we perceive besides our own ideas or sensations? And is it not plainly repugnant that any one of these, or any combination of them, should exist unperceived?"

It is not unnatural therefore that such a clear stand against existence of objective world itself would naturally lead him to denounce all the contemporary attempts being made to model and understand the dynamics of the this world especially the logical foundation of Calculus. His view was later identified as subjective idealism and severely criticized by Lenin (1908) in his book Materialism and Empirio-criticism. That was in the year 1908, when Lenin, referring to the continuity of Berkley's philosophy in Mach's views, showed how the promoters of idealism despite being exposed time and again by scientific materialism, still continue to rise from the ashes. How correct this proposition was, will be evident, even after almost three centuries after Berkley, if we scan through some of the recent works in brightness perception. In proposing his Anchoring Theory of Lightness Perception (Barkeley, 1960), Alan Gilchrist echoes Berkley:
"As in many modern approaches, one can begin with a domain that, because it is sufficiently limited, allows a precise mathematical model. One then attempts to broaden the domain without loss of rigor. We argue that this approach has repeatedly failed. An alternative approach takes a wide swath of phenomena and tries to characterize, perhaps in fairly broad terms, the nature of these phenomena. Then one attempts to refine the characterization, without loss of scope. Our model is the product of the later approach. We defend vagueness and imprecision only as a temporary price to pay for progress" (bold font type has been used by the present researchers)

As a consequence of this approach Gilchrist does not even refer to the mathematical models, either that of Blakeslee and McCourt $(1997 ; 1999)$ or that of their predecessors like Kingdom and Moulden (1992), excepting for a passing comment in one of his recent research (Gilchrist, 2005).

But this direct revival of subjective vagueness is preceded by many more attempts to establish the more veiled form of idealism albeit in its objective form. While the subjective form of idealism relates the source of knowledge to subjective sensations alone, the objective form promulgates the dualism of the objective world and the perceiving subject and does not consider perception to have emerged only from the objective world as the primary source, through mechanisms like lateral inhibition or any other variety of spatial filtering. The promoters of this view tried to develop intrinsic image theories of lightness perception. One of the earliest intrinsic image theories was proposed by Wallach (1948). Presenting observers with two diskannulus displays, Wallach demonstrated that as long as the luminance ratios in the disk-annulus are maintained the same, disks of difference in luminance appear equal 
in lightness. One can see the difference in the two forms of idealism. Unlike the subjective vagueness, the intrinsic image model of Wallach proposes an arithmetic relationship, viz. a simple ratio of disk and annulus towards the perception of lightness values, but in no way takes into account how such a stimulus is processed in visual pathways, despite the fact that the concept of visual receptive field had already hit the ground in 1940 (Hartline, 1940). Naturally Wallach's simple ratio formula suffered from a severe shortcoming, although admittedly, the concept of luminance ratios at the edges goes far towards explaining the traditional problem of lightness constancy or the illumination independent constancy, which is sometimes referred to as the Type I constancy. It leads to the background independent lightness constancy or the Type II constancy. This implies that when the same piece of gray paper is viewed successively against different backgrounds, then although the luminance ratio across the paper edge changes dramatically, contrary to the ratio principle, the paper appears to change little in lightness. This constancy calls for some mechanism by virtue of which luminance values of even widely separated regions in the retinal image can be compared to carry out a sort of normalization. The Retinex theory of Land and McCann (1971) strengthened the intrinsic image theory by providing evidences and arguments suggesting that the visual system is indeed capable of deriving luminance ratios between two remote surfaces in the image. But no mechanism was suggested towards such computation, except the suggestion that possibly the luminance ratios at every edge encountered along an arbitrary path from one surface to its remote pair are mathematically integrated. Gilchrist (1977; 2006) carried forward this approach further by proposing that such edge integration should be preceded by a classification of edges in the visual system into two main categories, viz. the reflectance edges and the illuminance edges. On the one hand Gilchrist was influenced by the pioneer Gestalt psychologist Koffka (2004) who observed that:

"Not all gradients are equally effective as regards the appearance of a particular field part ..... clearly two parts at the same apparent distance will, ceteris paribus, belong more closely together than field parts organized in different planes"

On the other hand, it is also apparent from Gilchrist's standpoint that by demarcating between reflectance and illuminance edges, he was attempting to carry forward the views of Helmholtz (1866) who proposed that luminance of a region in the retinal image was always compared with the perceived intensity of illumination in that region of the visual scene, so that the ratio yielded reflectance of the surface. By incorporating the role of illumination from Koffka (2004), Gilchrist actually tried to highlight the observation of Gelb (1929) who showed that a piece of black paper appeared white when presented alone in a spotlight, but the same paper appeared much darker when a real white was placed next to it in the spotlight. A major allegation of the objective idealist school against the reductionist alias mechanical materialist approach of the contrast theorists is that all scientific developments in this direction following Gelb (1929) and the likes of Wolff (1933); Katona (1935) and specially Helson (1943) and Katz (1935) in solving the problem of lightness constancy (the luminance of any region of the retinal image can vary by a factor of no more than thirty to one as a function of the physical reflectance of that surface, but can vary as a factor of a billion to one as a function of the illumination on that surface, resulting in the fact that any given luminance value, which is a product of the surface reflectance and its illumination, can literally be perceived in any shade of gray, depending on its context in the image and yet perceive shades of surface grays with rough accuracy. This is what is referred to as the problem of lightness constancy), were stopped after World War II, because the spotlight of this research shifted to North America. With physiological evidences of lateral inhibition, the contrast theorists dominated the scene. They strongly expounded that the excitatory-inhibitory receptive fields rendering thereby the ideas of Gestalt theory as obsolete. The followers of Gestalt theory denounced the artificial conditions under which the contrast experiments were carried out. They complained that in such experiments the stimulus conditions were very restrictive and quite different from normal viewing conditions, viz., luminous patches in psychophysical experiments were presented in dark rooms. Relative luminance was misinterpreted as contrast and the Gestalt lessons, they claimed, were lost in the overenthusiasm to explain lightness at physiological level (Gilchrist et al., 1999). Also the early European works were never cited. It is not that the tradition of relational determination of lightness/ brightness totally disappeared from the nineteen forties. But these, according to Gilchrist et al. (1999), were interpreted as stimulus gradients, i.e. luminance of the target surface was either compared with a weighted average luminance of the retinal image (Helson, 1943) or looked upon as diskannulus luminance ratios (Wallach, 1948). Such views 
of Helson (1943) or Wallach (1948) were not materialist, but a form of objective idealism from the intrinsic image theorists. However everybody having such views, did not stick to that philosophy.

A striking example is Allan Gilchrist himself, who finally deserted the objective idealist camp, strengthened earlier by him by carrying forward the intrinsic image theories (Gilchrist, 1977) to finally join Bishop Berkley's (1709; 1707) school of subjective (Gestalt et al., 1999). He justifies such camp shifting by pointing out the supposed weaknesses of the intrinsic image models, especially with respect to anchoring.

Gilchrist et al. (1999) poses the problem with intrinsic image models in the following way:

"For instance, consider a pair of adjacent regions in the retinal image whose luminance values stand in a 5:1 ratio. This 5:1 ratio informs the visual system only about the relative lightness values of the two surfaces, not their specific or absolute lightness values. It informs only about the distance between the two gray shades on the phenomenal gray scale, not the specific location of either on that scale. There is an infinite family of pairs of gray shades that are consistent with the 5:1 ratio. For example if the 5 represents white, then the 1 represents middle gray. However the 5 might represent middle gray, in which case the 1 would represent black....."

This is the anchoring problem, the problem about how the visual system ties relative luminance values extracted from the retinal image to specific values of perceived black, white and gray, for which according to Gilchrist et al. (1999), one needs an anchoring rule that would define at least one point of contact (anchoring) between luminance values in the image and gray scale values along the phenomenal black-to-white scale in the visual system (Fig. 7).

Computational attempts have been taken by the intrinsic image theorists to approach this problem, like for instance, the stimulus gradient approach of Helson (1943), discussed earlier, where he proposes that a target surface whose luminance is equal to the average luminance in the retinal image appears middle gray, being above average appears light gray or white and being below appears dark gray or black-this being often referred to as the average luminance rule. Horn (1986) at MIT AI lab had, on the other hand, related the anchoring problem to the issue of normalization. But as usual, the subjective Gestalt theorists are less at home with such approaches and more with mystic heuristics and so Gilchrist et al. (1999) in their bid to solve the problem of anchoring, takes recourse to a passing statement of intrinsic image theorist Wallach(1976), who says in his book On Perception that the value of white is assigned to the highest luminance in the display and serves as the standard for darker surfaces. Interestingly, this rule, called the highest luminance rule, also serves the Retinex theory of Land and McCann (1971) and the computational theories of lightness by Horn (1986), a fact that serves to show that objective and subjective forms of idealism are only two sides of the same coin. Thus we see that while McCann (2004) continues to adopt the highest luminance rule, Land, his collaborator in setting up the Retinex theory (Land and McCann,1971) reverts to the average luminance rule in a later version of the Retinex theory (Land, 1983). The anchoring theory of Gilchrist also prefers the highest luminance rule. The heuristic anchoring rule that Gilchrist et al. (1999) proposes, is as follows:

For simple images, the brightest region appears white and the appearance of each darker region depends on its relationship to the white region, according to the formula:

$\mathrm{PR}=\mathrm{L}_{\mathrm{t}} / \mathrm{L}_{\mathrm{h}} \times 90 \%$

Where:

$\mathrm{PR}=$ Perceived reflectance

$\mathrm{L}_{\mathrm{t}}=$ The luminance of the target

$\mathrm{L}_{\mathrm{h}}=$ The highest luminance in the framework and 90\% is the reflectance of white

Then, they went on to integrate this approach with an area rule which states that in a simple display, when the darker of the two regions has the greater relative area, its lightness value goes up in direct proportion and the corresponding modified formula:

$$
\mathrm{PR}=\left(100 \mathrm{~A}_{\mathrm{d}}\right) / 50 \times\left(\mathrm{L}_{\mathrm{t}} / \mathrm{L}_{\mathrm{h}} \times 90 \%\right)+\left(\mathrm{A}_{\mathrm{d}}-50\right) / 50 \times(90 \%)
$$

where, $A_{d}$ is the area of the darker region, as a percentage of the total area in the field. Equation 5 shows that if $A_{d}$ represents half (i.e., $50 \%$ ) of the total area, it reduces to Eq. 6. As $A_{d}$ approaches $100 \%$, its perceived reflectance approaches $90 \%$ and between these two end points, there is a supposedly smooth transition. The lighter region has no lightness value other than white, but as $\mathrm{A}_{\mathrm{d}}$ grows, qualitative changes occur in the lighter region, first to fluorescence and finally to self-luminosity (Fig. 7). This phenomenon is in consonance with dialectical materialism, which states that quantitative changes do finally bring about qualitative changes. 
OnLine J. Biol. Sci., 10 (1): 17-35, 2010

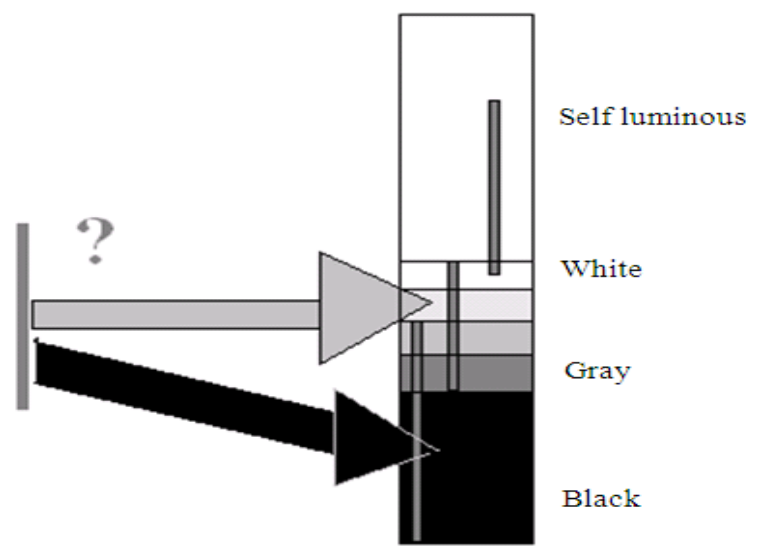

Fig. 7: The anchoring problem

The idealists like Gilchrist et al. (1999), who refuse to depend upon physiological findings but understand this principle, are driven to a similar position as their philosophical forerunner George Wilhelm Friedrich Hegel who wielded the weapon of dialectics to meet the demands of a crisis in idealism. Hence they conclude that in lightness perception such "qualitative change, not surprisingly, is difficult to capture mathematically", thus taking recourse to Kantian agnosticism which demarcates between the "thing in itself" and "the thing for us", i.e., what can be modeled and understood and what cannot. Indeed according to Engels, "the dialectic of Hegel was placed upon its head; or rather, turned off its head, on which it was standing and placed upon its feet" (Engels, 1886).

Domine, quo vadis? So then, we are now put in a very peculiar position: While discussing about the brightness induction, we notice that all recent mathematical models to understand the context dependent directional nature of brightness induction are continually increasing the quantity of parameters involved in such modeling without any major qualitative leap. Again at the end of the last section, we see that Gestalt school, in contrast, is providing clues to such qualitative changes in understanding, even as they shun mathematical models of the visual system. How then can a comprehensive theory of brightness perception emerge? In which direction should the research proceed from here? Before we analyze this situation any further, let us quickly take a glimpse of some of the recent activities of the intrinsic image theorists, which we have not yet covered in our review. This will aid in the development of a better understanding of the mathematical model-based approaches currently in vogue towards explaining brightness perception.
We have already mentioned, that the observations on White effect provided a fillip to Gestalt psychologists to offer alternative explanations of brightness perception that rejected the idea that brightness induction would occur as a result of spatial filtering through visual pathways. Todorovic (1997); Zaidi et al. (1997) represent one such school of contemporary intrinsic image theorists who put forward an alternative explanation of White effect based upon the $\mathrm{T}$-junction rule. $\mathrm{T}$-junction is the meeting place of three different intensity regions in an image: two collinear regions form the stem and the other flanking region forms the top of the T-junction. The brightness of the region that shares edges with the other regions of the T-junction, predominantly depends on the luminance of its collinear region and is in the direction of SBC effect. In White stimulus, one of the gray patches form four T-junctions with the flanking black bars and the collinear white bar, while for the other one, the situation is just reversed (Fig. 5 and 6). Hence, Tjunction rule predicts that a gray patch on the collinear white bar will look darker than that on a black bar. Similarly, the anchoring model of Gilchrist et al. (1999), discussed above, argues that in terms of the Gestalt grouping principles the principal grouping factor is the T-junction. Anderson (2001) also suggests a lightness rule, by which the T-junctions in the display of White effect trigger the parsing of the targets into multiple layers. The computational model based on higher level groupings forwarded by Ross and Pessoa (2000) in its simplified form, also segments visual scenes by means of T-junctions. All these models, based upon T-junction analysis and/or perceptual inferences, fail to predict the perceived brightness in Howe's (2001) stimulus (Fig. 10). In that case the junction based intrinsic image theorists provide alternative explanations. For the Howe's stimulus, T-junction rule predicts the same brightness perception to the gray test patch on white bar as that in White effect. This is contrary to the perception of thirty out of thirty three naive observers who report that either the left gray bar appears lighter than the right one (17 observers) or that both are perceived equally bright (13 observers) (Howe, 2001). Howe (2001) himself has suggested (Grossberg, 1994; 2001) that the effect may be explained under the assumption that the stimulus configuration results in the formation of four illusory contours, which effectively change the $\mathrm{T}$-junctions to $\mathrm{X}$-junctions. Thus a tradition of intrinsic image theorists continues in the form of such perceptual groupings based upon T-, X-and Psi junctions in images, although none of such junction analysis could predict the increase in strength of the brightness induction with respect to the increase in 
spatial frequency of the square grating in a White stimulus (i.e., in Fig. 5 or 8 as compared to Fig. 6).

These junction based image theories, however, are not the only computational models in recent years. Amidst the proliferation of these intrinsic image theorists, significantly, a short but very interesting work has been published quite recently by the spatial filtering school by Blakeslee et al. (2005) which, unlike the previous research of Blakeslee and McCourt (1997; 1999; 2004), bears evidences of a possible qualitative leap for this materialist school towards understanding the bi-directional nature of brightness induction. Considering its importance, let us discuss this research a little bit in details.

Blakeslee et al. (2005) measured brightness induction in a set of chosen stimuli and illustrated that White effect and SBC actually occupy opposite ends of a continuum of stimuli in which the Howe stimulus is the mid-point. They also simultaneously compared their psychophysical measurements with the predictions of their cortical multi-scale Oriented Difference Of Gaussian (ODOG) model, amalgamated with the concept of contrast normalization (Blakeslee and McCourt, 2004).

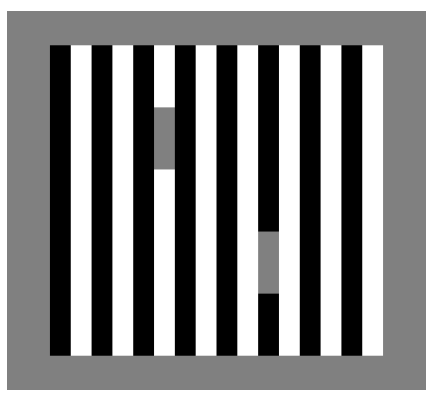

Fig. 8: The assimilation end of Blakeslee et al. (2005) continuum. The classical White effect

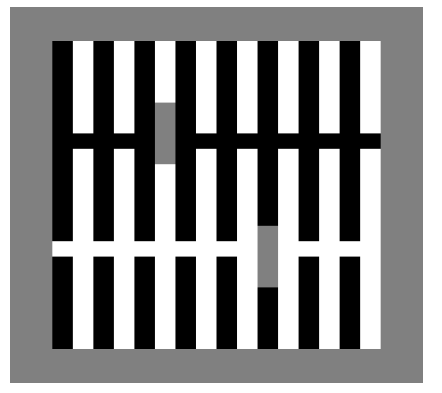

Fig. 9: A variation of the classical white effect. Alternate flanking bars are starting to be filled with opposite brightness resulting in reduced assimilation according to experimental results
They started with the original White's stimulus to end up with the stimulus that produces SBC while basically increasing the amount of filling of alternate flanking bars with opposite brightness (Fig. 8-12). In both the White's stimulus and its slightly perturbed variant, the reports of the subjects in the psychophysical experiments, as well as their contrast normalized ODOG model, provided the same output for both Fig. 8 and 9, that a gray test patch on white coaxial bar is perceived darker than the same test patch situated on the black bar. So the direction of brightness perception follows the same pattern as in case of assimilation, with a decrease in the group mean of the observers as well as the predicted induction strength by the model for Fig. 9. The designers of these set of experiments, continued to increase the amount of filling up to a limit when the column height matched that of the test patch, so that it resulted in Howe's stimulus. This stimulus is yet to be dealt with by the subjective Gestalt theorists, like for example using anchoring model.

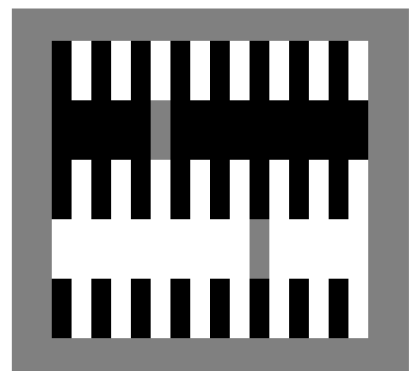

Fig. 10: The Howe stimulus with alternate flanking bars being filled up to the height of the test patches. Ambiguity in brightness perception results in psychophysical experiments

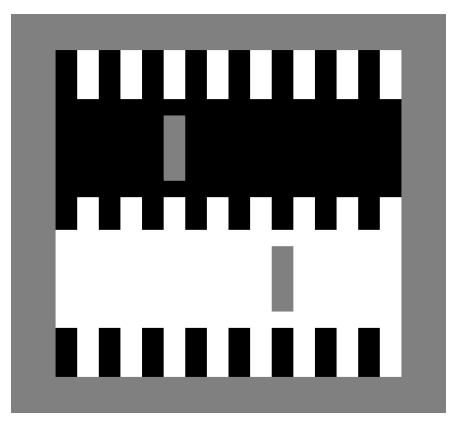

Fig. 11: The Howe stimulus variant with the filling of alternate flanking bars exceeding the height of the test patches. Ambiguity reduces in the opposite direction i.e., brightness contrast. Reversal in brightness induction shows quantity to quality transition 


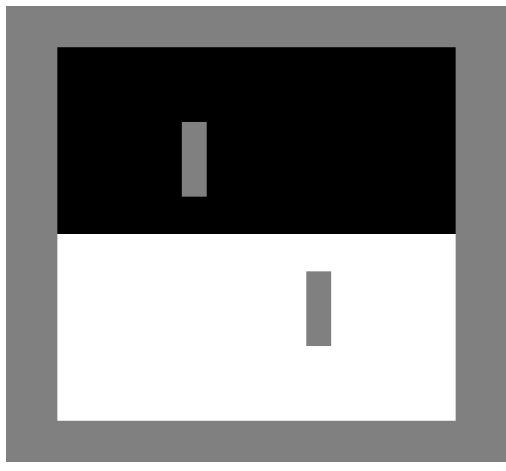

Fig. 12: Further fill in results in the classical simultaneous brightness contrast illusion

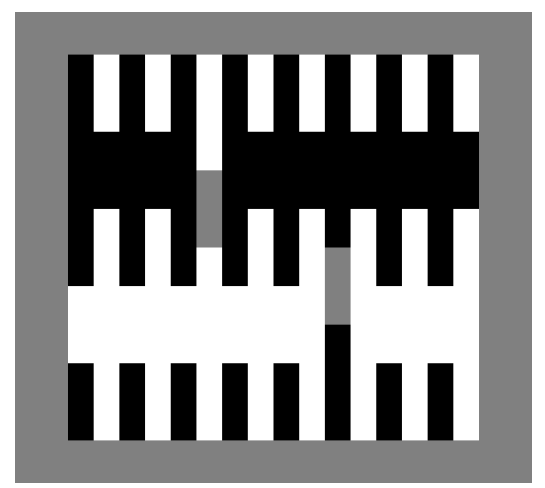

Fig. 13: Vertical displacement of test patch from classical Howe stimulus results in the Anderson's stimulus. Yet another qualitative reversal in the direction of assimilation occurs, but with a much reduced magnitude in that direction, as reported in experiments

There is no satisfactory explanation of this stimulus through any junction rule, although the application of $\mathrm{X}$-junction rules did manage to achieve some success. In keeping with the observations of Howe's thirty subjects, the subjects in Blakeslee et al. (2005), also report that the brightness difference of the two test patches in Howe stimulus (Fig. 10) is either much reduced from the previous two stimuli (i.e., Fig. 8 and 9), disappears altogether or reverses sign in the direction of the next two (Fig. 11 and 12). In case of the experiments carried out by Blakeslee and McCourt, 6 of the 8 observers report disappearance or reversal of induction direction, while even for the other two there is a further diminution in induction magnitude compared to Fig. 9. In other words, the Howe stimulus occupies the midpoint of a continuum encompassing these five stimuli. It should however be admitted that neither through the contrast normalized (globally)
ODOG model nor by quantitatively increasing the number of parameters and resorting to the modified ODOG models like Locally normalized ODOG (LODOG) and the Frequency-specific LODOG (FLODOG) (Robinson et al., 2007), it is possible to separately explain the varying observations of these subjects. The ODOG model merely reflects the trend of induction reversal. This results from a possible weakness in understanding the dialectics of quantitative-qualitative and its reflection in the proposed theoretical models. Yet the works of these experimentalists as well as their predecessors like Anderson, in designing these illusions and experimentally connecting them in a continuum, by quantitatively increasing the amount of fill-in of the alternate bars that result in qualitative changes in brightness induction, does bear imprints of materialistic dialectics. As we see that in keeping with this continuity, finally, a complete brightness shift in the direction of brightness contrast occurs in Fig. 11, where the fill-in of the alternate columns exceeds the test patch dimension itself. The strength of such induction increases even further in Fig. 12 since the fill-in now further increases to an extent where the stimulus assumes the form of the classical simultaneous brightness contrast stimulus as proposed by Heinmann (1955). A confirmatory test for this stimuli continuum was suggested by Blakeslee et al. (2005) by introducing the Anderson variant of Howe stimulus. This is shown in Fig. 13. Here the test patches themselves are vertically shifted from their Howe stimulus location, so that the amount of fill-in effectively decreases but not to the extent of Fig. 8 or even Fig. 9. So, the subjects are found to report only another reversal of direction towards brightness assimilation but with a lesser magnitude as compared to Fig. 9 and of course compared to the original White effect (Fig. 8). Thus this confirmatory test towards the existence of a continuous brightness perception scale from assimilation to contrast successfully verifies the proposition of Blakeslee et al. (2005). The contrast normalized ODOG model is also found to represent this experimental trend.

Why we are yet to find more authentic theories towards brightness perception, which are compatible with the neurophysiological, anatomical and psychophysical observations? Is it the compartmentalization of science and the alienation of these branches in vision science from each other is the prime cause of the impediment? In keeping with what we have already mentioned about the characteristics of any complex system, one should infer while understanding a complex phenomenon like visual 
information processing through these various branches of science, that the inherent contradiction between the independent behavior of each of these branches and the mutual control of one on the other through a network connectivity of these individual models, actually gives rise to the emerging properties of the complex system as a whole. Any attempt to construct a comprehensive model of such a complex reality should reflect this fact. It would be worthwhile to quote a few lines from Darwin (2003), the father of evolutionary biology regarding the complexity of the eye itself, leave alone the eye-brain complex:

"To suppose that the eye with all its inimitable contrivances for adjusting the focus to different distances, for admitting different amounts of light and for the correction of spherical and chromatic aberration could have been formed by natural selection seems, I freely confess, absurd in the highest degree. When it was first said that the sun stood still and the world turned round, the common sense of mankind declared the doctrine false; but the old saying of Vox populi, vox Dei, as every philosopher knows, cannot be trusted in science. Reason tells me, that if numerous gradations from a simple and imperfect eye to one complex and perfect can be shown to exist, each grade being useful to its possessor, as is certainly the case; if further, the eye ever varies and the variations be inherited, as is likewise certainly the case and if such variations should be useful to any animal under changing conditions of life, then the difficulty of believing that a perfect and complex eye could be formed by natural selection, though insuperable by our imagination, should not be considered as subversive of the theory"

All attempts to model the present phenomenon of brightness perception should therefore consider the above mentioned aspects concerning anatomy, physiology and psychophysics of the visual system together in an appropriate connectivity, along with the external conditions like illumination, where these internal structures manifest themselves. Some very preliminary attempts to this end have been made in recent times by relating the phenomenon of psychophysical brightness perception to the physiology of the extra-classical receptive fields of ganglion cells in the retina (Ghosh et al., 2006).
Physiologists have observed for a long time, that a number of photoreceptor cells, lying outside the lateral inhibition based Classical Receptive Field (CRF) of ganglion cell, can modulate the behavior of that cell (Ikeda and Wright, 1972; Shou et al., 2000; Passaglia et al., 2000). Such modulation, from what is termed as the Extra Classical Receptive Field (ECRF), is probably nonlinear in nature (Zetzsche and Röhrbein, 2001). It has however been shown (Ghosh et al., 2005) that though stimulations in ECRF are known to elicit nonlinear responses in the retina, it is worthwhile to probe the efficacy of a simple linear mathematical model representing a spatial filter for the ECRF. Another study by (Ghosh and Pal, 2007) attempts to show that the illusions used by Ghosh et al. (2006) towards justifying their ECRF model also probably belong to three different classes as shown by Blakeslee et al. (2005), a class of assimilation, a class of contrast and a class of ambiguity as in Howe stimulus. But much work remains to be done, in setting up a crosstalk between psychology and neuroscience. For example, it remains a glaring fact that the different psychophysical models discussed so far, be it spatial filtering based or be it the intrinsic image theory based, fail to provide much insight into their connectivity with the parallel pathways in our central visual system, wellknown and well studied by anatomists and neurophysiologists alike, for a long time. These pathways are again broadly classified into three types, viz., the Parvocellular (P), the Magnocellular (M) and the Koniocellular $(\mathrm{K})$. They originate from different types ( $\mathrm{P}, \mathrm{M}$ and $\mathrm{K}$ ) of retinal ganglion cells (Monasterio and Gouras, 1975; Croner and Kaplan, 1995; Solomon et al., 2002; Xu et al., 2001) which give rise to $\mathrm{P}, \mathrm{M}$ and $\mathrm{K}$ channels segregated anatomically, physiologically and behaviorally (Shapley and Perry, 1986; Silviera and Perry, 1991; Schiller and Malpeli, 1978; Merigan et al., 1991). These channels send visual information from the retina to the cerebral cortex via LGN in thalamus. The visual cortex is also supposed to be divided into two pathways viz. the temporal and the parietal, one of which is specialized for motion processing and the other for color or form information processing (Ungerleider and Mishkin, 1982). Several studies (Merigan et al., 1991; Merigan and Maunsell, 1993) put indirect evidences that $M$ channel in subcortical pathway feeds input to motion pathway and $\mathrm{P}$ channel drives the color or form pathway of visual cortex. But by selective blocking of neuronal response of either P or M channels in LGN of macaque monkeys (Macaca fascicularis and M. nemstrina), several neurobiologists like Ferrera et al. (1992) came up with results, showing that in spite of the parallelism, there is 
indeed an intermixing of $\mathrm{P}$ and $\mathrm{M}$ channel contribution as early as in the visual area V4 and more interestingly even in many units of V1, providing evidence that both $\mathrm{M}$ and $\mathrm{P}$ channels probably make substantial and early contribution to neuronal response in color or form pathway (Valois et al., 2000). It is not unlikely therefore, that all the three (including $\mathrm{K}$ ) channels and not only $\mathrm{P}$, as is traditionally believed, may be involved in the construction of cortical brightness percept. It is worthwhile to explore if the complementary nature of these three pathways is helpful in explaining the bidirectional nature of brightness induction together with the ambiguous intermediate effects mentioned by (Blakeslee et al., 2005). But one hardly encounters such a dialogue between psychophysics and neuroscience. There are occasional attempts to understand the temporal dynamics of brightness perception, which indirectly search for a possible role of the parallel channels in perceiving brightness. These types of researches have been done by Valois et al. (1986); Rossi and Paradiso (1996) and in very recent times by Robinson et al. (2008) and also by Blakeslee and McCourt (2008). In neural modeling some recent works have been done by Wielaard and Sajda (2007) in modelling the non-linearities in extra-classical receptive fields, which appeared to be missing in the work of Ghosh et al. (2006). Wielaard and Sajda (2007) have also used a simplified concept of feed-forward pathways alone. Without the incorporation of the feedback pathways, these models of visual computation fail to surpass the limits of mechanical materialist approach. An attempt has recently been made Ghosh (2009) to use the cortico-geniculate feedbacks on the feed-forward model of Ghosh et al. (2006) for searching the possible pathway in central visual route. Another computational model with higher level figure-ground grouping for predicting the direction of brightness induction has been proposed Ghosh and Pal (2009) that strengthens the school of thought where recurrent interplay between bottom-up and top-down processing holds the key to visual perception Hotchstein and Ahissar (2002) It should however be borne in mind, that although the development of multi-disciplinary subjects, of new disciplines like complex systems, systems biology and so on as a defiance to the reductionist separation of physics from chemistry or biology, of experiment from theory or as in here, of psychophysics from anatomy, does bear signature of a revival in approach towards combining the micro and macro, the part and the whole, the particular and the general, one cannot but still be afraid that these streams will again lose their flow in the cruelly hot sand of eclecticism in the name of upholding holism. That such fear is not baseless, becomes evident from on one hand, a noticeable tendency of the scientific community to try to arrive again and again at 'grand unified' absolute truths from experiments in various partial branches, or totally refuting the existence scientific truth by highlighting the importance of external conditions and resorting to 'relativism' on the other.

To appreciate the importance of applying dialectical materialism in developing scientific theories, let us now conclude this chapter with a quotation from Sakata (1971) an accomplice of the great Japanese particle physicist H. Yukawa, who says that if only:

\section{"theoretical physics had been conscious of the dialectics of nature and learned the logic of high quality, they would have taken a more straightforward way to establish quantum mechanics....the methodology of Bohr and Heisenberg, though it worked well as an active weapon in constructing quantum mechanics, has frequently worked negatively in the recent development of theories of atomic nuclei and of elementary particles. This is due to the fact that the methodology consists of only a partial consciousness of the dialectics of nature. Indeed, a misleading methodology, if one applies it extensively as a creed, is always transferred into the opposition according to the well-known law of dialectics"}

Though these words of Sakata were in reference to the domain of modern physics, these are equally applicable for the present context as well. Unawareness about dialectical and historical materialism (Stalin, 1938) is hindering the development of theoretical psychophysics in particular and neural information processing in general, towards developing a well-connected consistent theory in lightness/brightness (Gilchrist, 2006) in perception, in spite of the many methodologies working well here and there as 'active weapon'.

\section{CONCLUSION}

Philosophy, in its truest sense, encompasses everything including Mathematics and Natural Sciences. However, as it stands today, Mathematics and Philosophy have cut out their individual niche and have developed as two complimentary tools, which are indispensable for studying, understanding and developing the theory of knowledge especially in natural science. While mathematics is the language through which scientific statements are precisely expressed, philosophy is the tool through which the 
statements can be interpreted, comprehended. Theoretical science relying solely upon mathematics is dominated by objective idealism or at best by mechanical materialism. On the other hand scientific pursuit of new theories devoid of mathematics and expressed solely through philosophy is likely to end up in the realm of crude subjectivity. Our journey through the history of vision science in general and brightness study in particular in this study, justifies the above statements. Shunning the path of mathematics, vision scientists from Bishop Berkeley (who rejected the necessity of the branch of calculus in mathematics in explaining the laws of nature) to Allan Gilchrist (who prefers 'vagueness and imprecision' over the 'limitations' of mathematical models) have thus led themselves to the path of solipsism. On the other hand, in this review we have shown that reliance upon mathematics sans dialectics, have led the intrinsic image theorists to dualism and the contrast theorists to metaphysics.

Another very interesting domain, we have attempted to study here, is the origin of Dialectics in science and philosophy. Contrary to the popular belief, this methodology was not introduced by the materialist school. Rather, the primitive form of dialectics, sharpened by the idealist philosophers, can be traced to the ancient Greek or oriental philosophies. Even in modern times, it was the idealist school of Hegel that strongly promoted dialectic thought process. In fact, before the development of modern science, materialism (which was mostly the philosophy of the underprivileged) was in its primitive form. The idealists (who were mostly from the privileged class) used dialectic to falsify the primitive materialism. In the post-renaissance period, with the advent of modern science and the unfurling of its varied beauties-starting from the quantum mechanics of subatomic particles, the gravity of black holes and the relativity of time and space to the enormous complexity of biological systems, materialism became a strong contender for idealism. However, the initial bottom-up materialist flurry of industrial economy completely lost its road amidst the drudgery of world wars, war economy and politics of intimidation, eking out only a forced topdown existence. Gilchrist (2005) had rightly mentioned about this change in scenario after World War II, with the focus shifting from the war bruised Europe to the least affected North America. But what he had not mentioned is the reason behind the rise of the Gestalt school. With the underprivileged too now fighting tooth and nail to bag their share of power and finally replace the privileged, the battle between religious idealism and dialectical materialism reached its zenith and out came dialectics again as a weapon of the idealists. Equipped with the concepts of Proximity, Similarity, Continuity, the Gestalt people started attacking the mechanical materialism of the crude contrast theorists who relied only upon internal contradiction and not the external conditions, like illumination, in which they flourish. The contrast theorists fought back and tried to incorporate these in formulating ratio-based theories where as if the external conditions cancel out. It is not a question of cancelling out, but a question of flourishing of the content within the appropriate form. If form gets cancelled out, content becomes vulnerable and the dialectical influences of form upon content or of superstructure upon base become apparent. In the light of this discussion, it has been demonstrated (Ghosh et al., 2009) that in visual perception of lightness distribution, external noise may assume importance in expressing an intrinsic property of the image.

Almost as a parallel to the social scenario, the scientific philosophy too, after the Second World War, remained indecisive and a truce emerged in the form of objective idealism or at best mechanical materialism. In such a situation the dialectical materialism got bound to its mechanical version and finally ushered in crude subjective idealism. Such trends are now becoming evident in scientific literature, with the subjectivists once again resorting to dialectics-the present Gestalt school taking recourse to the sharp weapons of dialectic laws like continuity, quantity-quality transition and so on to ensure that no remnant of materialism is left. However, one need not conclude that this would be the end of dialectic or of materialism. It should be remembered that the tool of dialectics was borrowed from the idealist camp of Hegel and was combined with the mechanical materialism in classical German philosophy represented by Feuerbach, only to transform it qualitatively to materialist dialectics in order to challenge the very edifice of idealism. Lateral inhibition based contrast theories would also hopefully be substantiated not only by the basic law of dialectics on which it rests upon viz. the unity of opposites, but also through the incorporation of the other laws like connectivity, quantity-quality transition or negation of the negation (Stalin, 1938; Tse Tung, 1937; Engels, 1877; Lenin, 1895-1916) so as to challenge all sorts of mysticisms in vision science and in brightness perception domain. The recent researches both in experimental psychophysics as well as in mathematical modeling, that have been discussed or referred to in this study, are showing signs of such a future in the offing. In order to ensure that such synthesis should be dialectic and not eclectic, it would require identifying the proper mathematics towards quantitatively 
representing complex phenomena as mentioned in the Introduction, a mathematics that can quantify the interaction between the part and the whole, through dialectical rules.

\section{REFERENCES}

Anderson, B., 2001. Contrasting theories white's illusion. Perception, 30: 1499-1501. http://www.ncbi.nlm.nih.gov/pubmed:118177 56

Anderson, J.R., 2005. Cognitive Psychology and Its Implications. 7th Edn., Worth Publishers, WH Freeman and Co., New York, ISBN: 10: 1429219483, pp: 608.

Barkeley, G., 1760. A Treatise Concerning the Principles of Human Knowledge, Filiquarian, LLC, ISBN: 10: 1599868075, pp: 124.

Barkeley, G., 1709. An essay towards a new theory of vision ebook.

http://www.gutenberg.org/etext/4722 http://psychclassics.yorku.ca/Berkeley/vision.htm

Blakeslee, B. and M.E. McCourt, 1997. Similar mechanisms underlie simultaneous brightness contrast and grating induction. Vis. Res., 37: 2849-2869. DOI: 10.1016/S0042-6989(97)00086-2

Blakeslee, B. and M.E. McCourt, 1999. A multiscale spatial filtering account of the White effect, simultaneous brightness contrast and grating induction. Vis. Res., 39: 4361-4377. DOI: 10.1016/S0042-6989(99)00119-4

Blakeslee, B. and M.E. McCourt, 2004. A unified theory of brightness contrast and assimilation incorporating oriented multiscale spatial filtering and contrast normalization. Vis. Res., 44: 2483-2503. DOI: $10.1016 /$ j.visres.2004.05.015

Blakeslee, B. and M.E. McCourt, 2008. Nearly instantaneous brightness induction. J. Vis., 8: 1-8. PMID: 18318641

Blakeslee, B., W. Pasieka and M.E. McCourt, 2005. Oriented multiscale spatial filtering and contrast normalization: A parsimonious model of brightness induction in a continuum of stimuli including White, Howe and simultaneous brightness contrast. Vis. Res., 45: 607-615. DOI: 10.1016/j.visres.2004.09.027

Chalmers, D.J., 1996. The Conscious Mind: In Search of a Fundamental Theory. 1st Edn., Oxford University Press, USA., ISBN-10: 0195117891, pp: 432.

Croner, L.J. and E. Kaplan, 1995. Receptive fields of P and $\mathrm{M}$ ganglion cells across the primate retina. Vis.
Res., 35: 7-24. DOI: 10.1016/00426989(94)E0066-T

Darwin, C., 2003. The Origin of Species. 150th Edn., Signet Classics, ISBNL 10: 0451529065, pp: 576.

Dember, W.N., 1964. Visual Perception: The Nineteenth Century. 1st Edn., John Wiley and Sons.

Engels, F., 1886. Ludwig Feuerbach and the End of Classical German Philosophy. Marx-Engels Selected Works, Progress Publishers of the Soviet Union, pp: 594-632 eBook. http://www.marxists.org/archive/marx/works/1886/ ludwig-feuerbach/

Engels, F., 1883. Dialectics of Nature. Marx-Engels Collected Works. 1st Edn., Progress Publishers of the Soviet Union in collaboration with Lawrence and Wishart (London) and International Publishers, New York, eBook. http://www.marxists.org/archive/marx/works/ 1883/don/index.htm

Enroth, C.C. and J.G. Robson, 1966. The contrast sensitivity of the retinal ganglion cells of the cat. J. Physiol. Lond., 187: 517-552. PMID: 16783910

Engels, F., 1877. Dialectics: Quantity and Quality and Negation of the Negation: Anti-Duhring. Herr Eugen Dühring's Revolution in Science. 1st Edn., Progress Publishers, New York. http://www.marxists.org/archive/marx/works/1877/ anti-duhring/index.htm

Ferrera, V.P., T.A. Nealey and J.R.H. Maunsell, 1992. Mixed parvocellular and mangocellular geniculate signals in visual area V4. Nature, 358: 756-758. DOI: $10.1038 / 358756 a 0$

Gelb, A., 1929. Color Constancy of Visual Objects, In: Handbuch der Normalen and Pathogischen Physiologie, Von Bethe, W.A. (Ed.)., Vol. 12, Springer, Berlin, pp: 594-678.

Ghosh, K., S. Sarkar and K. Bhaumik, 2009. A possible mechanism of stochastic resonance in the light of an extended classical receptive field model of retinal ganglion cells. Biol. Cybernet., 100: 351-359. DOI: $10.1007 / \mathrm{s} 00422-009-0306-9$

Ghosh, K., 2009. Understanding the mechanism of brightness perception through a new LGN model (manuscript communicated).

Ghosh, K. and S.K. Pal, 2009. Some Insights into Brightness perception of images in the light of a new computational model of figure-ground segregation. IEEE Trans. Syst. Man Cybernet. Part A: Syst. Man (In Press).

Ghosh, K. and S.K. Pal, 2007. Explaining and classifying brightness perception illusions by a new receptive field approach. Perception, 36: 54-55. 
http://www.perceptionweb.com/abstract.cgi?id $=\mathrm{v} 070407$ dt 1st Jan 2010.

Ghosh, K., S. Sarkar and K. Bhaumik, 2005. A possible mechanism of zero-crossing detection using the concept of extended classical receptive field model of retinal ganglion cells. Biol. Cybernet., 93: 1-5. DOI: 10.1007/s00422-005-0580-0

Ghosh, K., S. Sarkar and K. Bhaumik, 2006. A possible explanation of the low-level brightness-contrast illusions in the light of an extended classical receptive field model of retinal ganglion cells. Biol. Cybernet., 94: 89-96. DOI: 10.1007/s00422-0050038-4

Gilchrist, A., 1977. Perceived lightness depends on perceived spatial arrangement. Science, 195: 185-187. DOI: $10.1126 /$ science. 831266

Gilchrist, A.L., C. Kossyfidis, F. Bonato, T. Agostini and J. Cataliotti et al., 1999. An anchoring theory of lightness perception. Psychol. Rev., 106: 795-834.

Gilchrist, A., 2006. Seeing in Black and White. 1st Edn., Oxford University Press, USA., ISBN: 10: 0195187164, pp: 448.

Gilchrist, A.L., 2005. Lightness perception: Seeing one color through another. Curr. Biol., 15: R330-R332. DOI: 10.1016/j.cub.2005.04.028

Gregory, R.L., 1972. Seeing as thinking-an active theory of perception. Times Literary Supplement, pp: 707-708.

Grossberg, S., 1994. 3-D vision and figure-ground separation by visual cortex. Percept. Psychophys., 55: 48-120. PMID: 8036093

Grossberg, S., 2001. Theory versus speculation in visual perception. Perception, 30: 1505-1507. DOI: $10.1068 / \mathrm{p} 3012 \mathrm{ds}$

Hartline, H.K., 1940. The receptive fields of optic nerve fibers. Am. J. Physiol., 130: 690-699.

Heidelberger, M., 2004. (Translated by Cynthia Klohr), Nature From Within: Gustav Theodor Fechner and His Psychophysical Worldview. 1st Edn., University of Pittsburgh Press, ISBN: 10: 0822942100, pp: 456.

Heinmann, E.G., 1955. Simultaneous brightness induction as a function of inducing and testfield luminances. J. Exp. Psychol., 50: 89-96. PMID: 13242747

Helson, H., 1943. Some factors and implications of color constancy. J. Opt. Soc. Am., 33: 555-567. DOI: 10.1364/JOSA.33.000555

Helson, H., 1963. Studies of anomalous contrast and assimilation. J. Opt. Soc. Am., 53: 179-184. DOI: 10.1364/JOSA.53.000179
Hong, S.W. and S.K. Shevell, 2004. Brightness contrast and assimilation from patterned inducing backgrounds. Vis. Res., 44: 35-43. DOI: 10.1016/j.visres.2003.07.010

Horn, B.K.P., 1986. Robot Vision, The MIT Press; MIT Press Ed edition (March 13, 1986), Cambridge, MA., pp: 480.

Hotchstein, S. and M. Ahissar, 2002. View from the top: Hierarchies and reverse hierarchies in the visual system. Neuron, 36: 791-804. DOI: 10.1016/S0896-6273(02)01091-7

Howe, P.D.L., 2001. A comment on the Anderson (1997), the Todorovic (1997) and the Ross and Pessoa (2000) explanations of White's effect. Perception, 30: 1023-1026. DOI: 10.1068/p3212

Hubel, D.H. and T.N. Wiesel, 1962 Receptive fields, binocular interaction and functional architecture in the cat visual cortex. J. Physiol. Lond., 160: 106-154. PMID: 14449617

Ikeda, H. and M.J. Wright, 1972. Functional organization of the periphery effect in retinal ganglion cells. Vis. Res., 12: 1857-1879. DOI: 10.1016/0042-6989(72)90076-4

Jameson, D. and L.M. Hurvich, 1989. Essay concerning color constancy. Ann Rev. Psychol., 40: 1-22. DOI: 10.1146/annurev.ps.40.020189.000245

Jameson, D., 1985. Opponent-Colors Theory In The Light Of Physiological Findings. In: Central and Peripheral Mechanisms of Color Vision, Ottoson, D. and S. Zeki (Eds.). MacMillan, London, pp: 83-102.

Katona, G., 1935. Color contrast and color constancy. J. Exp. Psychol., 18: 49-63.

Katz, D., 1935. The World of Color. 1st Edn., Kegan Paul, Trench, Trubner, London, pp: 300.

Kingdom, F.A.A. and B. Moulden, 1992. A multichannel approach to brightness coding. Vis. Res., 32: $\quad 1565-1582$. DOI: $\quad 10.1016 / 0042-$ 6989(92)90212-2

Koffka, K., 2004. Principles of Gestalt Psychology 1935. Routledge, Taylor and Francis, pp: 718.

Land, E.H., 1983. Recent advances in retinex theory and some implications for cortical computations: Color vision and the natural image. Proc. Natl. Acad. Sci. USA. Phys., 80: 5163-5169. PMID: 6576382

Land, E.H. and J.J. McCann, 1971. Lightness and retinex theory. J. Opt. Soc. Am., 61: 1-11. DOI: 10.1364/JOSA.61.000001

Lenin, V.I., 1895. Philosophical Notebooks. Collected Works, Progress Publishers, Moscow, http://www.marxists.org/archive/lenin/works/cw/v olume38.htm 
Lenin, V.I., 1908. Materialism and Empirio-Criticism: Critical Comments on a Reactionary Philosophy. Lenin Collected Works, Progress Publishers, 1972, Moscow, pp: 17-362. http://www.marx.org/archive/lenin/works/1908/me c/index.htm

Monasterio, D.F.M. and P. Gouras, 1975. Functional properties of ganglion cells of the rhesus monkey retina. J. Physiol. Lond., 251: 167-195. PMID: 810576

Valois, D.R.L., N.P. Cottaris, L.E. Mahon, S.D. Elfar and J.A. Wilson, 2000. Spatial and temporal receptive fields of geniculate and cortical cells and directional selectivity. Vis. Res., 40: 3685-3702. DOI: 10.1016/S0042-6989(00)00210-8

Valois, D.R.L., M.A. Webster, D.K.K. Valois and B. Lingelbach, 1986. Temporal properties of brightness and color induction. Vis. Res., 26: 887897. DOI: 10.1016/0042-6989(86)90147-1

Mandler, J.M. and G. Mandler, 1964. Thinking: From Association to Gestalt. Greenwood Press Reprint; ISBN: 10: 031323261X, pp: 300.

Marr, D. and E. Hildreth, 1980. Theory of edge detection. Proc. R. Soc. Lond., 207: 187-217. PMID: 6102765

Marr, D., 1982. Vision: A Computational Investigation into the Human Representation and Processing of Visual Information. 1st Edn., WH Freeman and Company, New York, ISBN: 13: 978-0716715672, pp: 397.

McCann, J.J., 2004. Capturing a black cat in shade: past and present of Retinex color appearance models. J. Electron. Imaging, 13: 36-47. DOI: $10.1117 / 1.163583$

McCourt, M.E., 1982. A spatial frequency dependent grating-induction effect. Vis. Res., 22: 119-134. DOI: 10.1016/0042-6989(82)90173-0

Merigan, W.H., L.M. Katz and J.R.H. Maunsell, 1991. The effects of parvocellular lateral geniculate lesions on the acuity and contrast sensitivity of macaque monkeys. J. Neurosci., 11: 994-1001. PMID: 2010820

Merigan W.H. and J.R.H. Maunsell, 1993. How parallel are the primate visual pathways? Annu. Rev. Neurosci., 16: 369-402. PMID: 8460898

Palmer, S.E., 1999. Vision Science: Photons to Phenomenology. MIT Press, 1st Edn., Cambridge, Massachusetts, ISBN:13: 978-0262161831, pp: 832.

Passaglia, C.L., C.C. Enroth and J.B. Troy, 2001. Effects of remote stimulation on the mean firing rate of cat retinal ganglion cells. J. Neurosci., 21: 5794-5803. PMID: 11466451
Ratliff, F. and H.K. Hartline, 1959. The responses of limulus optic nerve fibers to patterns of illumination on the receptor mosaic. J. Gen. Physiol., 42: 1241-1255. PMID: PMC2194959

Ratliff, F., 1965. Mach Bands: Quantitative Studies on Neural Network in the Retina. 1st Edn., HoldenDay, San Francisco, pp: 365

Robinson, A.E. and D.V.R. Sa, 2008. Brief presentations reveal the temporal dynamics of brightness induction and White's illusion. Vis. Res., 48: 2370-2381. DOI: 10.1016/j.visres.2008.07.023

Robinson, A.E., P.S. Hammon and D.V.R. Sa, 2007. Explaining brightness illusions using spatial filtering and local response normalization. Vis. Res., 47: 1631-1644. DOI: 10.1016/j.visres.2007.02.017

Rodieck, R.W. and J. Stone, 1965. Analysis of receptive fields of cat retinal ganglion cells. J. Neurophysiol, 28: 833-849. PMID: 5867882

Ross, W.D. and L. Pessoa, 2000. Lightness from contrast: A selective integration model. Percept. Psychophys., 62: 1160-1181 PMID: 11019614

Rossi, A.F. and M.A. Paradiso, 1996. Temporal limits of brightness induction and mechanism of brightness perception. Vis. Res., 36: 1391-1398. DOI: 10.1016/0042-6989(95)00206-5

Sakata, S., 1971. Philosophical and Methodological Problems in Physics. Prog. Theor. Phys., 50: 1-8. DOI: 10.1143/PTPS.50.1

Schiller, P.H. and J.G. Malpeli, 1978. Functional specificity of lateral geniculate nucleus laminae of the rhesus monkey. J. Neurophysiol., 41: 788-797. PMID: 96227

Shapley, R. and V.H. Perry, 1986. Cat and monkey retinal ganglion cells and their visual functional roles. Trends Neurosci., 9: 229-235. DOI: 10.1016/0166-2236(86)90064-0

Shou, T., W. Wang and H. Yu, 2000. Orientation biased extended surround of the receptive field of cat retinal ganglion cells. Neuroscience, 98: 207-212. DOI: 10.1016/S0306-4522(00)00129-9

Silviera, L.C.L. and V.H. Perry, 1991. The topography of magnocellular projecting ganglion cells (M ganglion cells) in the primate retina. Neuroscience, 40: 217-37. DOI: 10.1016/0306-4522(91)90186-R

Solomon, S.G., A.J.R. White and P.R. Martin, 2002. Extraclassical receptive field properties of parvocellular, magnocellular and koniocellular cells in the primate lateral geniculate nucleus. J. Neurosci., 22: 338-349. PMID: 11756517

Stalin, J., 1940. Dialectical and Historical Materialism. 1st Edn., International Publishers Co. http://www.marxists.org/reference/archive/stalin/w orks/1938/09.htm 
Tse-Tung, M., 1937. On contradiction, selected works. Foreign Languages Press, Peking, China. http://www.marxists.org/reference/archive/mao/sel ected-works/volume-1/mswv1_17.htm

Todorovic, D., 1997. Lightness and junctions. Perception, 26: 379-395. DOI: 10.1068/p260379

Ungerleider, L.G. and M. Mishkin, 1982. Two Cortical Visual Systems. In: The Analysis of Visual Behavior, Ingle, D.J., R.J.W. Mansfield and M.S. Goodale (Eds.). MIT Press, Mass, Cambridge, ISBN: 13: 978-0-262-09022-3, pp: 54-86.

Wallach, H., 1948. Brightness constancy and the nature of achromatic colors. J. Exp. Psychol, 38: 310-324. PMID: 18865234

Wallach, H., 1976. On Perception. 1st Edn., Quadrangle/The New York Times Book Co., New York, pp: 490.

White, M., 1981. The effect of the nature of the surround on the perceived lightness of gray bars within square-wave test gratings. Perception, 10: 215-230. DOI: 10.1068/p100215

White, M., 1979. A new effect of pattern on perceived lightness. Perception, 8: 13-416. DOI: 10.1068/p080413

White, M. and T. White, 1985. Counterphase lightness induction. Vis. Res., 25: 1331-1335. PMID: 4072013
Wielaard, J. and P. Sajda, 2007. Dependence of response properties on sparse connectivity in a spiking neuron model of the lateral geniculate nucleus. J. Neurophysiol., 98: 3292-3308. DOI: 10.1152/jn.00654.20070022-3077/07

Wolff, W., 1933. Concerning the contrast-causing effect of transformed colors. Psychol. Forschung, 18: 90-97. DOI: 10.1007/BF02409628

Xu, X., M.I. Jennifer, J.D. Allison, J.D. Boyd, A.B. Bonds and V.A. Casagrande, 2001. A comparison of koniocellular, magnocellular and parvocellular receptive field properties in the lateral geniculate nucleus of the owl monkey (Aotus trivirgatus). J. Physiol., 531: 203-218. DOI: 10.1111/j.14697793.2001.0203j.X

Zaidi, Q., B. Spehar and M. Shy, 1997. Induced effects of background and foregrounds in threedimensional configurations: The role of $\mathrm{T}$ junctions. Perception, 26: 395-408. DOI: $10.1068 / \mathrm{p} 260395$

Zetzsche, C. and F. Röhrbein, 2001. Nonlinear and extra-classical receptive field properties and the statistics of natural scenes. Network, 2: 331-350. PMID: 11563533 